\title{
Research Article \\ On the Solution of Double-Diffusive Convective Flow due to a Cone by a Linearization Method
}

\author{
Mahesha Narayana and Precious Sibanda \\ School of Mathematical Sciences, University of KwaZulu-Natal, Private Bag X01, Scottsville, \\ Pietermaritzburg 3209, South Africa \\ Correspondence should be addressed to Precious Sibanda, sibandap@ukzn.ac.za
}

Received 8 September 2011; Accepted 14 October 2011

Academic Editor: Renat Zhdanov

Copyright (C) 2012 M. Narayana and P. Sibanda. This is an open access article distributed under the Creative Commons Attribution License, which permits unrestricted use, distribution, and reproduction in any medium, provided the original work is properly cited.

\begin{abstract}
The paper details the use of a nonperturbation successive linearization method to solve the coupled nonlinear boundary value problem due to double-diffusive convection from an inverted cone. Diffusion-thermo and thermal-diffusion effects have been taken into account. The governing partial differential equations are transformed into ordinary differential equations using a suitable similarity transformation. The SLM is based on successively linearizing the governing nonlinear boundary layer equations and solving the resulting higher-order deformation equations using spectral methods. The results are compared with the limited cases from previous studies and results obtained using the Matlab inbuilt bvp4c numerical algorithm and a shooting technique that uses Runge-Kutta-Fehlberg (RKF45) and Newton-Raphson schemes. These comparisons reveal the robustness and validate the usage of the linearisation method technique. The results show that the nonperturbation technique in combination with the Chebyshev spectral collocation method is an efficient numerical algorithm with assured convergence that serves as an alternative to numerical methods for solving nonlinear boundary value problems.
\end{abstract}

\section{Introduction}

The convection driven by two different density gradients with differing rates of diffusion is widely known to as "double-diffusive convection" and is an important fluid dynamics phenomenon (see Mojtabi and Charrier-Mojtabi [1]). The study of double-diffusive convection has attracted attention of many researchers during the recent past due to its occurrence in nature and industry. Oceanography is the root of double-diffusive convection in natural settings. The existence of heat and salt concentrations at different gradients and the fact that they diffuse at different rates lead to spectacular double-diffusive instabilities known as "salt-fingers" (see Stern [2,3]). The formation of salt-fingers can also be observed in laboratory settings. Double-diffusive convection occurs in the sun where temperature and helium diffusions take place at different rates. Convection in magma chambers and 
sea-wind formations are among other manifestations of double-diffusive convection in nature. Migration of moisture through air contained in fibrous insulations, grain storage systems, the dispersion of contaminants through water-saturated soil, crystal growth, the underground disposal of nuclear wastes, the formation of microstructures during the cooling of molten metals, and fluid flows around shrouded heat-dissipation fins are among other industrial applications of double-diffusive convection.

The inherent instabilities due to double-diffusive convection have been investigated by, among others, Nield [4], Baines and Gill [5], Guo et al. [6], Khanafer and Vafai [7], Sunil et al. [8], and Gaikwad et al. [9]. Double-diffusive convection due to horizontal, inclined, and vertical surfaces embedded in a porous medium has been studied by, among others, Cheng [10, 11], Nield and Bejan [12], and Ingham and Pop [13]. Chamkha [14] investigated the coupled heat and mass transfer by natural convection of Newtonian fluids about a truncated cone in the presence of magnetic field and radiation effects. Yih [15] examined the effect of radiation in convective flow over a cone.

Though heat and mass transfer happens simultaneously in a moving fluid, the relations between the fluxes and the driving potentials are generally complicated. It should be noted that the energy flux can be generated by both temperature and composition gradients. The energy flux caused by a composition gradient gives rise to the Dufour or diffusionthermo effect. Mass fluxes created by temperature gradient lead to the Soret or thermaldiffusion effect. These effects are in collective known as cross-diffusion effects. The crossdiffusion effect has been extensively studied in gases, while the Soret effect has been studied both theoretically and experimentally in liquids, see Mortimer and Eyring [16]. They used an elementary transition state approach to obtain a simple model for Soret and Dufour effects in thermodynamically ideal mixtures of substances with molecules of nearly equal size. In their model, the flow of heat in the Dufour effect was identified as the transport of the enthalpy change of activation as molecules diffuse. The results were found to fit the Onsager reciprocal relationship, Onsager [17].

In general, the cross-diffusion effects are small compared to the effects described by Fourier and Fick's laws (Mojtabi and Charrier-Mojtabi [1]) and can therefore be neglected in many heat and mass-transfer processes. However, it has been shown in a number of studies that there are exceptions in areas such as in geosciences where cross-diffusion effects are significant and cannot be ignored, see for instance Kafoussias and Williams [18], Awad et al. [19], and the references therein. With this view point, many investigators included crossdiffusion effects in the study of double-diffusive convection in fluid flows involving bodies of various geometries. Alam et al. [20] investigated the Dufour and Soret effects on steady combined free-forced convective and mass transfer flow past a semi-infinite vertical flat plate of hydrogen-air mixtures. They used the fourth-order Runge-Kutta method to solve the governing equations of motion. Their study showed that the Dufour and Soret effects should not be neglected. Shateyi et al. [21] investigated the effects of diffusion-thermo and thermaldiffusion on MHD fluid flow over a permeable vertical plate in the presence of radiation and hall current. Awad and Sibanda [22] used the homotopy analysis method to study heat and mass transfer in a micropolar fluid subject to Dufour and Soret effects.

Most boundary value problems in fluid mechanics are solved numerically using either the shooting method or the implicit finite difference scheme in combination with a linearization technique. These methods have their associated difficulties and failures in handling situations where solutions either vary sharply over a domain or problems that exhibit multiple solutions. These limitations necessitate the development of computationally improved semianalytical methods for solving strongly nonlinear problems. There are many 
different semianalytical methods to solve nonlinear boundary value problems, among them, the variational iteration method, the homotopy perturbation method [23-25], the Adomian decomposition method [26, 27], homotopy analysis method [28], and the spectral-homotopy analysis methods $[29,30]$. These iterative methods may sometimes fail to converge or give slow convergence for strongly nonlinear problems or problems involving large parameters. Yildirim [31] applied He's homotopy perturbation method to solve the Cauchy reactiondiffusion problem and compared his results with analytical solutions in certain test cases. Yildirim and Pinar [32] obtained periodic solutions of nonlinear reaction-diffusion equations arising in mathematical biology using the exp-function method. Yildirim and Sezer [33] found analytical solutions of linear and nonlinear space-time fractional reaction-diffusion equations (STFRDE) on a finite domain using the homotopy perturbation method (HPM). Yildirim et al. [34] presented approximate analytical solutions of the biochemical reaction model by the multistep differential transform method (MsDTM) and validated the results by comparing with the fourth-order Runge-Kutta method.

Ganji et al. [35] solved the nonlinear Jeffery-Hamel flow problem using two semianalytical methods, the variational iteration method (VIM) and the homotopy perturbation method. Ghafoori et al. [36] solved the equation for a nonlinear oscillator using the differential transform method (DTM). They compared DTM solutions with those obtained using the variational iteration method and the homotopy perturbation method. Joneidi et al. [37] used three analytical methods, the homotopy analysis method (HAM), homotopy perturbation method, and the differential transform method, to solve the Jeffery-Hamel flow problem. Babaelahi et al. [38] studied the heat transfer characteristics in an incompressible electrically conducting viscoelastic boundary layer fluid flow over a linear stretching sheet. They solved the flow equations using the optimal homotopy asymptotic method (OHAM) and validated their results by comparing the OHAM solutions with Runge-Kutta solutions.

In this study, we use a nonperturbation, semianalytic successive linearization method (see Makukula et al. $[39,40]$ ) to investigate double-diffusive convection from a cone in a viscous incompressible fluid subject to cross-diffusion effects. The study is an extension of the work by Ece [41] to include mass transfer and cross-diffusion effects. The linearization method iteratively linearizes the nonlinear equations to give a system of higher-order deformation equations that are then solved using the Chebyshev spectral collocation method.

\section{Mathematical Formulation}

Consider a vertical down-pointing cone with half-angle $\Omega$ immersed in a viscous incompressible liquid. The $x$-axis is along the surface of the cone, and the $y$-axis coincides with the outward normal to the surface of the cone. The origin is at the vertex of the cone, see Figure 1 . The surface of the cone is subject to a linearly varying temperature $T_{w}\left(>T_{\infty}\right)$ where $T_{\infty}$ is the ambient temperature.

Following the usual boundary layer and Boussinesq approximations, the basic equations governing the steady state dynamics of a viscous incompressible liquid are given by

$$
\begin{gathered}
\frac{\partial}{\partial x}(r u)+\frac{\partial}{\partial y}(r v)=0 \\
u \frac{\partial u}{\partial x}+v \frac{\partial u}{\partial y}=v \frac{\partial^{2} u}{\partial y^{2}}+g \beta\left(T-T_{\infty}\right) \cos \Omega+g \beta^{*}\left(C-C_{\infty}\right) \cos \Omega
\end{gathered}
$$




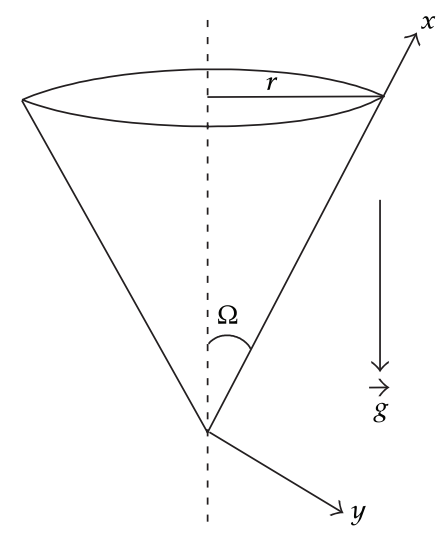

Figure 1: Schematic of the problem.

$$
\begin{aligned}
& u \frac{\partial T}{\partial x}+v \frac{\partial T}{\partial y}=\alpha \frac{\partial^{2} T}{\partial y^{2}}+k_{1} \frac{\partial^{2} C}{\partial y^{2}} \\
& u \frac{\partial C}{\partial x}+v \frac{\partial C}{\partial y}=D \frac{\partial^{2} C}{\partial y^{2}}+k_{2} \frac{\partial^{2} T}{\partial y^{2}}
\end{aligned}
$$

where $u$ and $v$ are the velocity components in the $x$ and $y$ directions, respectively, $r=x \sin \Omega$ is the local radius of the cone, $v$ is the kinematic viscosity, $\rho$ is the density, $g$ is the acceleration due to gravity, $\beta$ is the coefficient of thermal expansion, $\beta^{*}$ is the coefficient of solutal expansion, $T$ is the temperature, $C$ is the concentration, $\alpha$ is the thermal diffusivity, $D$ is the species diffusivity, and $k_{1}, k_{2}$ are cross-diffusion coefficients.

The boundary conditions for (2.1) have the form

$$
\begin{gathered}
u=v=0, \quad T=T_{w}=T_{\infty}+T_{r}\left(\frac{x}{L}\right), \quad C=C_{w}=C_{\infty}+C_{r}\left(\frac{x}{L}\right) \quad \text { at } y=0, \\
u \rightarrow 0, \quad T \longrightarrow T_{\infty}, \quad C \longrightarrow C_{\infty} \quad \text { as } y \longrightarrow \infty .
\end{gathered}
$$

Here, the subscripts $w$ and $\infty$ refer to the surface and ambient conditions, respectively, $T_{r}$ and $C_{r}$ are positive constants, and $L$ is a characteristic length.

We introduce the dimensionless variables

$$
(X, Y, R)=\frac{\left(x, y \mathrm{Gr}^{1 / 4}, r\right)}{L}, \quad(U, V)=\frac{\left(u, v \mathrm{Gr}^{1 / 4}\right)}{U_{0}}, \quad \bar{T}=\frac{T-T_{\infty}}{T_{w}-T_{\infty}}, \quad \bar{C}=\frac{C-C_{\infty}}{C_{w}-C_{\infty}},
$$

where the reference velocity $U_{0}$ and Grashof number $G r$ are defined, respectively, as

$$
U_{0}=\left[g \beta L\left(T_{w}-T_{\infty}\right) \cos \Omega\right]^{1 / 2}, \quad G r=\left(\frac{U_{0} L}{v}\right)^{2}
$$


On using the variables (2.3), the boundary-layer equations (2.1) reduce to

$$
\begin{gathered}
\frac{\partial}{\partial X}(R U)+\frac{\partial}{\partial Y}(R V)=0 \\
U \frac{\partial U}{\partial X}+V \frac{\partial U}{\partial Y}=\frac{\partial^{2} U}{\partial Y^{2}}+\bar{T}+\lambda \bar{C} \\
U \frac{\partial \bar{T}}{\partial X}+V \frac{\partial \bar{T}}{\partial Y}=\frac{1}{\operatorname{Pr}}\left[\frac{\partial^{2} \bar{T}}{\partial Y^{2}}+\mathrm{D}_{\mathrm{f}} \frac{\partial^{2} \bar{C}}{\partial Y^{2}}\right], \\
U \frac{\partial \bar{C}}{\partial X}+V \frac{\partial \bar{C}}{\partial Y}=\frac{1}{\operatorname{Sc}}\left[\frac{\partial^{2} \bar{C}}{\partial Y^{2}}+\operatorname{Sr} \frac{\partial^{2} \bar{T}}{\partial Y^{2}}\right] .
\end{gathered}
$$

The nondimensional parameters appearing in (2.5)-(2.8) are the buoyancy ratio $\lambda$, the Prandtl number Pr, the Schmidt number Sc, Dufour number $D_{f}$, and Soret number Sr defined, respectively, as

$$
\begin{array}{rlr}
\lambda=\frac{\beta^{*}}{\beta}\left(\frac{C_{w}-C_{\infty}}{T_{w}-T_{\infty}}\right), & \operatorname{Pr}=\frac{v}{\alpha}, \quad \text { Sc }=\frac{v}{D}, \\
D_{\mathrm{f}}=\frac{k_{1}}{\alpha}\left(\frac{C_{w}-C_{\infty}}{T_{w}-T_{\infty}}\right), & \mathrm{Sr}=\frac{k_{2}}{D}\left(\frac{T_{w}-T_{\infty}}{C_{w}-C_{\infty}}\right) .
\end{array}
$$

Assuming $T_{w}-T_{\infty}=T_{r}$ and $C_{w}-C_{\infty}=C_{r}$, the boundary conditions (2.2) can be written as

$$
\begin{aligned}
& U=V=0, \quad \bar{T}=X, \quad \bar{C}=X \quad \text { at } Y=0, \\
& U \rightarrow 0, \quad \bar{T} \longrightarrow 0, \quad \bar{C} \longrightarrow 0 \quad \text { as } Y \longrightarrow \infty .
\end{aligned}
$$

We now introduce the stream function $\psi(X, Y)$ such that

$$
U=\frac{1}{R} \frac{\partial \psi}{\partial Y^{\prime}}, \quad V=-\frac{1}{R} \frac{\partial \psi}{\partial X^{\prime}}
$$

so that the continuity equation (2.5) is satisfied identically. The boundary layer equations (2.6)-(2.8) can be written in terms of the stream function as

$$
\begin{gathered}
R \frac{\partial^{3} \psi}{\partial Y^{3}}+\frac{\partial(\psi, \partial \psi / \partial Y)}{\partial(X, Y)}+\frac{1}{X}\left(\frac{\partial \psi}{\partial Y}\right)^{2}+R^{2}(\bar{T}+\lambda \bar{C})=0 \\
R \frac{\partial^{2} \bar{T}}{\partial Y^{2}}+\operatorname{Pr} \frac{\partial(\psi, \bar{T})}{\partial(X, Y)}+R D_{\mathrm{f}} \frac{\partial^{2} \bar{C}}{\partial Y^{2}}=0 \\
R \frac{\partial^{2} \bar{C}}{\partial Y^{2}}+\operatorname{Sc} \frac{\partial(\psi, \bar{C})}{\partial(X, Y)}+R \operatorname{Sr} \frac{\partial^{2} \bar{T}}{\partial Y^{2}}=0 .
\end{gathered}
$$


The boundary conditions (2.10) in terms of the stream function are

$$
\begin{aligned}
& \frac{\partial \psi}{\partial X}=\frac{\partial \psi}{\partial Y}=0, \quad \bar{T}=X, \quad \bar{C}=X \quad \text { at } Y=0 \\
& \frac{\partial \psi}{\partial Y} \longrightarrow 0, \quad \bar{T} \longrightarrow 0, \quad \bar{C} \longrightarrow 0 \quad \text { as } Y \longrightarrow \infty
\end{aligned}
$$

We further introduce the following similarity variables

$$
\psi(X, Y)=X R f(Y), \quad \bar{T}(X, Y)=X \theta(Y), \quad \bar{C}(X, Y)=X \phi(Y)
$$

Using (2.14), (2.12) along with boundary conditions (2.13) reduces to the following two-point boundary value problem

$$
\begin{gathered}
f^{\prime \prime \prime}+2 f f^{\prime \prime}-f^{\prime 2}+\theta+\lambda \phi=0, \\
\theta^{\prime \prime}+\operatorname{Pr}\left(2 f \theta^{\prime}-f^{\prime} \theta\right)+\mathrm{D}_{\mathrm{f}} \phi^{\prime \prime}=0, \\
\phi^{\prime \prime}+\operatorname{Sc}\left(2 f \phi^{\prime}-f^{\prime} \phi\right)+\operatorname{Sr} \theta^{\prime \prime}=0, \\
f(0)=f^{\prime}(0)=0, \quad \theta(0)=\phi(0)=1, \\
f^{\prime}(\infty) \longrightarrow 0, \quad \theta(\infty) \longrightarrow 0, \quad \phi(\infty) \longrightarrow 0 .
\end{gathered}
$$

The primes in (2.15)-(2.18) denote differentiation with respect to $Y$.

\section{Successive Linearization Method}

The successive linearization method (see Makukula et al. $[39,40]$ ) is used to solve the boundary value problem (2.15)-(2.18). We assume that the functions $f(Y), \theta(Y)$, and $\phi(Y)$ may be expanded in series form as

$$
\begin{aligned}
& f(Y)=f_{i}(Y)+\sum_{m=0}^{i-1} F_{m}(Y) \\
& \theta(Y)=\theta_{i}(Y)+\sum_{m=0}^{i-1} \Theta_{m}(Y), \quad i=1,2,3, \ldots \\
& \phi(Y)=\phi_{i}(Y)+\sum_{m=0}^{i-1} \Phi_{m}(Y)
\end{aligned}
$$


where $f_{i}, \theta_{i}$, and $\phi_{i}$ are unknown functions and $F_{m}, \Theta_{m}$, and $\Phi_{m},(m \geq 1)$ are approximations that are obtained by recursively solving the linear part of the equation that results from substituting (3.1) in (2.15)-(2.17). Substituting (3.1) in the governing (2.15)-(2.17), we obtain

$$
\begin{gathered}
f_{i}^{\prime \prime \prime}+a_{1, i-1} f_{i}^{\prime \prime}+a_{2, i-1} f_{i}^{\prime}+a_{3, i-1} f_{i}+\theta_{i}+\lambda \phi_{i}+\left[2 f_{i} f_{i}^{\prime \prime}-f_{i}^{2}\right]=r_{1, i-1,} \\
\theta_{i}^{\prime \prime}+b_{1, i-1} \theta_{i}^{\prime}+b_{2, i-1} \theta_{i}+b_{3, i-1} f_{i}^{\prime}+b_{4, i-1} f_{i}+\operatorname{Pr}\left[2 f_{i} \theta_{i}^{\prime}-f_{i}^{\prime} \theta\right]+\mathrm{D}_{\mathrm{f}} \phi_{i}^{\prime \prime}=r_{2, i-1}, \\
\phi_{i}^{\prime \prime}+c_{1, i-1} \phi_{i}^{\prime}+c_{2, i-1} \theta_{i}+c_{3, i-1} f_{i}^{\prime}+c_{4, i-1} f_{i}+\operatorname{Sc}\left[2 f_{i} \phi_{i}^{\prime}-f_{i}^{\prime} \phi\right]+\operatorname{Sr} \theta_{i}^{\prime \prime}=r_{3, i-1},
\end{gathered}
$$

where the coefficient parameters $a_{k, i-1}(k=1,2,3), b_{k, i-1}, c_{k, i-1}(k=1, \ldots, 4)$, and $r_{k, i-1}(k=$ $1,2,3)$ are defined as

$$
\begin{aligned}
& a_{1, i-1}=2 \sum_{m=0}^{i-1} F_{m}, \quad a_{2, i-1}=-2 \sum_{m=0}^{i-1} F_{m}^{\prime}, \quad a_{3, i-1}=2 \sum_{m=0}^{i-1} F_{m}^{\prime \prime} \\
& b_{1, i-1}=2 \operatorname{Pr} \sum_{m=0}^{i-1} F_{m}, \quad b_{2, i-1}=-\operatorname{Pr} \sum_{m=0}^{i-1} F_{m}^{\prime}, \quad b_{3, i-1}=-\operatorname{Pr} \sum_{m=0}^{i-1} \Theta_{m}, \quad b_{4, i-1}=2 \operatorname{Pr} \sum_{m=0}^{i-1} \Theta_{m}^{\prime}, \\
& c_{1, i-1}=2 \operatorname{Sc} \sum_{m=0}^{i-1} F_{m}, \quad c_{2, i-1}=-\mathrm{Sc} \sum_{m=0}^{i-1} F_{m}^{\prime} \quad \mathcal{c}_{3, i-1}=-\mathrm{Sc} \sum_{m=0}^{i-1} \Phi_{m}, \quad c_{4, i-1}=2 \mathrm{Sc} \sum_{m=0}^{i-1} \Phi_{m}^{\prime}, \\
& r_{1, i-1}=-\left[\sum_{m=0}^{i-1} F_{m}^{\prime \prime \prime}+2 \sum_{m=0}^{i-1} F_{m} \sum_{m=0}^{i-1} F_{m}^{\prime \prime}-\left(\sum_{m=0}^{i-1} F_{m}^{\prime}\right)^{2}+\sum_{m=0}^{i-1} \Theta_{m}+\lambda \sum_{m=0}^{i-1} \Phi_{m}\right] \\
& r_{2, i-1}=-\left[\sum_{m=0}^{i-1} \Theta_{m}^{\prime \prime}+\operatorname{Pr}\left(2 \sum_{m=0}^{i-1} F_{m} \sum_{m=0}^{i-1} \Theta_{m}^{\prime}-\sum_{m=0}^{i-1} F_{m}^{\prime} \sum_{m=0}^{i-1} \Theta_{m}\right)+\mathrm{D}_{\mathrm{f}} \sum_{m=0}^{i-1} \Phi_{m}^{\prime \prime}\right], \\
& r_{3, i-1}=-\left[\sum_{m=0}^{i-1} \Phi_{m}^{\prime \prime}+\operatorname{Sc}\left(2 \sum_{m=0}^{i-1} F_{m} \sum_{m=0}^{i-1} \Phi_{m}^{\prime}-\sum_{m=0}^{i-1} F_{m}^{\prime} \sum_{m=0}^{i-1} \Phi_{m}\right)+\operatorname{Sr} \sum_{m=0}^{i-1} \Theta_{m}^{\prime \prime}\right] .
\end{aligned}
$$

Starting from the initial approximations

$$
F_{0}(Y)=1-e^{-Y}-Y e^{-Y}, \quad \Theta_{0}(Y)=e^{-Y}, \quad \Phi_{0}(Y)=e^{-Y}
$$

which are chosen to satisfy the boundary conditions (2.18), the subsequent solutions $F_{m}, \Theta_{m}$, $\Phi_{m}, m \geq 1$ are obtained by successively solving the linearized form of (3.2) given below

$$
\begin{gathered}
F_{i}^{\prime \prime \prime}+a_{1, i-1} F_{i}^{\prime \prime}+a_{2, i-1} F_{i}^{\prime}+a_{3, i-1} F_{i}+\Theta_{i}+\lambda \Phi_{i}=r_{1, i-1}, \\
\Theta_{i}^{\prime \prime}+b_{1, i-1} \Theta_{i}^{\prime}+b_{2, i-1} \Theta_{i}+b_{3, i-1} F_{i}^{\prime}+b_{4, i-1} F_{i}+\mathrm{D}_{\mathrm{f}} \Phi_{i}^{\prime \prime}=r_{2, i-1}, \\
\Phi_{i}^{\prime \prime}+c_{1, i-1} \Phi_{i}^{\prime}+c_{2, i-1} \Phi_{i}+c_{3, i-1} F_{i}^{\prime}+c_{4, i-1} F_{i}+\operatorname{Sr}_{i}^{\prime \prime}=r_{3, i-1},
\end{gathered}
$$


subject to the boundary conditions

$$
F_{i}(0)=F_{i}^{\prime}(0)=F_{i}^{\prime}(\infty)=0, \quad \Theta_{i}(0)=\Theta_{i}(\infty)=0, \quad \Phi_{i}(0)=\Phi_{i}(\infty)=0 .
$$

Once each solution $F_{i}, \Theta_{i}$, and $\Phi_{i}(i \geq 1)$ has been found from iteratively solving (3.5) for each $i$, the functions $f(Y), \theta(Y)$, and $\phi(Y)$ are obtained as series

$$
f(Y) \approx \sum_{i=0}^{M} F_{i}(Y), \quad \theta(Y) \approx \sum_{i=0}^{M} \Theta_{i}(Y), \quad \phi(Y) \approx \sum_{i=0}^{M} \Phi_{i}(Y),
$$

where $M$ is the order of SLM approximation. Equations (3.5) are integrated using the Chebyshev spectral collocation method [42-44]. The unknown functions are defined by the Chebyshev interpolating polynomials with the Gauss-Lobatto points defined as

$$
Y_{j}=\cos \frac{\pi j}{N}, \quad j=0,1, \ldots, N,
$$

where $N$ is the number of collocation points used. The physical region $[0, \infty)$ is transformed into the domain $[-1,1]$ using the domain truncation technique in which the problem is solved on the interval $\left[0, Y_{\infty}\right]$ instead of $[0, \infty)$. This leads to the mapping

$$
\frac{Y}{Y_{\infty}}=\frac{\xi+1}{2}, \quad-1 \leq \xi \leq 1
$$

where $Y_{\infty}$ is the known number used to invoke the boundary condition at infinity. The unknown functions $F_{i}, \Theta_{i}$, and $\Phi_{i}$ are approximated at the collocation points by

$$
\begin{gathered}
F_{i}(\xi) \approx \sum_{k=0}^{N} F_{i}\left(\xi_{k}\right) T_{k}\left(\xi_{j}\right), \quad \Theta_{i}(\xi) \approx \sum_{k=0}^{N} \Theta_{i}\left(\xi_{k}\right) T_{k}\left(\xi_{j}\right), \\
\Phi_{i}(\xi) \approx \sum_{k=0}^{N} \Phi_{i}\left(\xi_{k}\right) T_{k}\left(\xi_{j}\right), \quad j=0,1, \ldots, N,
\end{gathered}
$$

where $T_{k}$ is the $k$ th Chebyshev polynomial defined as

$$
T_{k}(\xi)=\cos \left[k \cos ^{-1}(\xi)\right] .
$$

The derivatives of the variables at the collocation points are represented as

$$
\begin{gathered}
\frac{d^{n} F_{i}}{d Y^{n}}=\sum_{k=0}^{N} \mathbf{D}_{k j}^{n} F_{i}\left(\xi_{k}\right), \quad \frac{d^{n} \Theta_{i}}{d Y^{n}}=\sum_{k=0}^{N} \mathbf{D}_{k j}^{n} \Theta_{i}\left(\xi_{k}\right), \\
\frac{d^{n} \Phi_{i}}{d Y^{n}}=\sum_{k=0}^{N} \mathbf{D}_{k j}^{n} \Phi_{i}\left(\xi_{k}\right), \quad j=0,1, \ldots, N,
\end{gathered}
$$


where $n$ is the order of differentiation and $\mathbf{D}=\left(2 / Y_{\infty}\right) \Phi$ where $\Phi$ is the Chebyshev spectral differentiation matrix (see, [42-44]). Substituting (3.8)-(3.12) in (3.5)-(3.6) leads to the matrix equation

$$
\mathbf{A}_{i-1} \mathbf{X}_{i}=\mathbf{B}_{i-1}
$$

in which $\mathbf{A}_{i-1}$ is a square matrix of order $(3 N+3)$ and $\mathbf{X}_{i}, \mathbf{B}_{i-1}$ are $(3 N+3) \times 1$ column vectors defined by

$$
\mathbf{A}_{i-1}=\left[\begin{array}{lll}
A_{11} & A_{12} & A_{13} \\
A_{21} & A_{22} & A_{23} \\
A_{31} & A_{32} & A_{33}
\end{array}\right], \quad \mathbf{X}_{i}=\left[\begin{array}{c}
\mathbf{F}_{i} \\
\mathbf{\Theta}_{i} \\
\mathbf{\Phi}_{i}
\end{array}\right], \quad \mathbf{B}_{i-1}=\left[\begin{array}{l}
\mathbf{r}_{1, i-1} \\
\mathbf{r}_{2, i-1} \\
\mathbf{r}_{3, i-1}
\end{array}\right],
$$

with

$$
\begin{gathered}
\mathbf{F}_{i}=\left[F_{i}\left(\xi_{0}\right), F_{i}\left(\xi_{1}\right), \ldots, F_{i}\left(\xi_{N-1}\right), F_{i}\left(\xi_{N}\right)\right]^{T}, \\
\boldsymbol{\Theta}_{i}=\left[\Theta_{i}\left(\xi_{0}\right), \Theta_{i}\left(\xi_{1}\right), \ldots, \Theta_{i}\left(\xi_{N-1}\right), \Theta_{i}\left(\xi_{N}\right)\right]^{T}, \\
\mathbf{\Phi}_{i}=\left[\Phi_{i}\left(\xi_{0}\right), \Phi_{i}\left(\xi_{1}\right), \ldots, \Phi_{i}\left(\xi_{N-1}\right), \Phi_{i}\left(\xi_{N}\right)\right]^{T}, \\
\mathbf{r}_{1, i-1}=\left[r_{1, i-1}\left(\xi_{0}\right), r_{1, i-1}\left(\xi_{1}\right), \ldots, r_{1, i-1}\left(\xi_{N-1}\right), r_{1, i-1}\left(\xi_{N}\right)\right]^{T}, \\
\mathbf{r}_{2, i-1}=\left[r_{2, i-1}\left(\xi_{0}\right), r_{2, i-1}\left(\xi_{1}\right), \ldots, r_{2, i-1}\left(\xi_{N-1}\right), r_{2, i-1}\left(\xi_{N}\right)\right]^{T}, \\
\mathbf{r}_{3, i-1}=\left[r_{3, i-1}\left(\xi_{0}\right), r_{3, i-1}\left(\xi_{1}\right), \ldots, r_{3, i-1}\left(\xi_{N-1}\right), r_{3, i-1}\left(\xi_{N}\right)\right]^{T}, \\
A_{11}=\mathbf{D}^{3}+\mathbf{a}_{1, i-1} \mathbf{D}^{2}+\mathbf{a}_{2, i-1} \mathbf{D}+\mathbf{a}_{3, i-1}, \quad A_{12}=\mathbf{I}, \quad A_{13}=\lambda \mathbf{I}, \\
A_{21}=\mathbf{b}_{3, i-1} \mathbf{D}+\mathbf{b}_{4, i-1}, \quad A_{22}=\mathbf{D}^{2}+\mathbf{b}_{1, i-1} \mathbf{D}+\mathbf{b}_{2, i-1}, \quad A_{23}=\mathbf{D}_{\mathbf{f}} \mathbf{D}^{2}, \\
A_{31}=\mathbf{c}_{3, i-1} \mathbf{D}+\mathbf{c}_{4, i-1}, \quad A_{32}=\mathbf{S r D}^{2}, \quad A_{33}=\mathbf{D}^{2}+\mathbf{c}_{1, i-1} \mathbf{D}+\mathbf{c}_{2, i-1} .
\end{gathered}
$$

In the above definitions, $\mathbf{a}_{k, i-1}(k=1,2,3), \mathbf{b}_{k, i-1}, \mathbf{c}_{k, i-1}(k=1, \ldots, 4), \mathbf{D}_{\mathbf{f}}$, and $\mathbf{S r}$ are diagonal matrices of order $(N+1)$ and $\mathbf{I}$ is the identity matrix of order $(N+1)$. Finally, the solution of the problem is obtained as

$$
\mathbf{X}_{i}=\mathbf{A}_{i-1}^{-1} \mathbf{B}_{i-1}
$$

Thus, starting with the initial solutions $F_{0}, \Theta_{0}$, and $\Phi_{0}$, a sequence of approximations $\sum_{0}^{k} F_{k}$, $\sum_{0}^{k} \Theta_{k}$, and $\sum_{0}^{k} \Phi_{k}, k=1,2, \ldots, M$ are obtained until (3.7) holds. The convergence of this iteration process depends on the parameter values, that is, for small parameter values, the iterates converge faster as compared to large parameter values.

\section{Skin Friction, Heat and Mass Transfer Coefficients}

The parameters of engineering interest in heat and mass transport problems are the skin friction coefficient $C_{f}$, the Nusselt number $\mathrm{Nu}$, and the Sherwood number Sh. These parameters characterize the surface drag, the wall heat and mass transfer rates, respectively. 
The shearing stress at the surface of the cone $\tau_{w}$ is defined as

$$
\tau_{w}=\frac{\mu}{X}\left[\frac{\partial u}{\partial y}\right]_{y=0} \frac{\mu U_{0}}{L G r^{-1 / 4}} f^{\prime \prime}(0)
$$

where $\mu$ is the coefficient of viscosity. The skin friction coefficient at the surface of the cone is defined as

$$
C_{f}=\frac{\tau_{w}}{(1 / 2) \rho U_{0}^{2}}
$$

Using (4.1) in (4.2), we obtain the following relation

$$
C_{f} \mathrm{Gr}^{1 / 4}=2 f^{\prime \prime}(0)
$$

The heat transfer rate at the surface of the cone is defined as

$$
q_{w}=\frac{-k}{X}\left[\frac{\partial T}{\partial y}\right]_{y=0}=\frac{-k\left(T_{w}-T_{\infty}\right)}{L G r^{-1 / 4}} \theta^{\prime}(0),
$$

where $k$ is the thermal conductivity of the fluid. The Nusselt number is defined as

$$
\mathrm{Nu}=\frac{L}{k} \frac{q_{w}}{T_{w}-T_{\infty}}
$$

Using (4.4) in (4.5), the dimensionless wall heat transfer rate is obtained as follows:

$$
\mathrm{NuGr}^{-1 / 4}=-\theta^{\prime}(0)
$$

The mass flux at the surface of the cone is defined as

$$
J_{w}=\frac{-D}{X}\left[\frac{\partial C}{\partial y}\right]_{y=0}=\frac{-D\left(C_{w}-T_{\infty}\right)}{L G r^{-1 / 4}} \phi^{\prime}(0)
$$

and the Sherwood is defined as

$$
\text { Sh }=\frac{L}{D} \frac{J_{w}}{T_{w}-T_{\infty}}
$$

Using (4.7) in (4.8), the dimensionless wall mass transfer rate is obtain as

$$
\operatorname{ShGr}^{-1 / 4}=-\phi^{\prime}(0)
$$


Table 1: Comparison of SLM results for single component convection $\left(\lambda=0\right.$ and $\left.D_{f}=S r=0\right)$ with Ece [41].

\begin{tabular}{lcccc}
\hline Pr & \multicolumn{2}{c}{ Ece [41] } & \multicolumn{2}{c}{ Present results } \\
& $f^{\prime \prime}(0)$ & $-\theta^{\prime}(0)$ & $f^{\prime \prime}(0)$ & $-\theta^{\prime}(0)$ \\
\hline 1 & 0.681482 & 0.638859 & 0.68148333 & 0.63885472 \\
10 & 0.433269 & 1.275548 & 0.43327825 & 1.27552888 \\
\hline
\end{tabular}

Table 2: Comparison of $f^{\prime \prime}(0),-\theta^{\prime}(0)$, and $-\phi^{\prime}(0)$ obtained by SLM with bvp4c and shooting methods for different values of $\mathrm{D}_{\mathrm{f}}$ and $\mathrm{Sr}$ with $\lambda=\operatorname{Pr}=\mathrm{Sc}=1$.

\begin{tabular}{|c|c|c|c|c|c|c|c|}
\hline \multirow{2}{*}{ Quantiy } & \multirow{2}{*}{$\mathrm{D}_{\mathrm{f}}$} & \multirow{2}{*}{ Sr } & \multicolumn{3}{|c|}{ SLM } & \multirow{2}{*}{ bvp4c } & \multirow{2}{*}{ Shooting } \\
\hline & & & $M=3$ & $M=4$ & $M=5$ & & \\
\hline \multirow{5}{*}{$f^{\prime \prime}(0)$} & 0.00 & 1.00 & 1.244372648 & 1.244372629 & 1.244372629 & 1.244372633 & 1.244373 \\
\hline & 0.25 & 0.75 & 1.233210690 & 1.233210687 & 1.233210687 & 1.233210690 & 1.233211 \\
\hline & 0.50 & 0.50 & 1.229002907 & 1.229002906 & 1.229002906 & 1.229002911 & 1.229003 \\
\hline & 0.75 & 0.25 & 1.233210690 & 1.233210687 & 1.233210687 & 1.233210690 & 1.233211 \\
\hline & 1.00 & 0.00 & 1.244372648 & 1.244372629 & 1.244372629 & 1.244372633 & 1.244373 \\
\hline \multirow{5}{*}{$-\theta^{\prime}(0)$} & 0.00 & 1.00 & 0.803753575 & 0.803753516 & 0.803753516 & 0.803753488 & 0.803754 \\
\hline & 0.25 & 0.75 & 0.750979670 & 0.750979649 & 0.750979649 & 0.750979625 & 0.750980 \\
\hline & 0.50 & 0.50 & 0.663129905 & 0.663129902 & 0.663129902 & 0.663129885 & 0.663130 \\
\hline & 0.75 & 0.25 & 0.553122477 & 0.553122494 & 0.553122494 & 0.553122487 & 0.553122 \\
\hline & 1.00 & 0.00 & 0.444121263 & 0.444121327 & 0.444121327 & 0.444121329 & 0.444121 \\
\hline \multirow{5}{*}{$-\phi^{\prime}(0)$} & 0.00 & 1.00 & 0.444121263 & 0.444121327 & 0.444121327 & 0.444121329 & 0.444121 \\
\hline & 0.25 & 0.75 & 0.553122477 & 0.553122494 & 0.553122494 & 0.553122487 & 0.553122 \\
\hline & 0.50 & 0.50 & 0.663129905 & 0.663129902 & 0.663129902 & 0.663129885 & 0.663130 \\
\hline & 0.75 & 0.25 & 0.750979670 & 0.750979649 & 0.750979649 & 0.750979625 & 0.750980 \\
\hline & 1.00 & 0.00 & 0.803753575 & 0.803753516 & 0.803753516 & 0.803753488 & 0.803754 \\
\hline
\end{tabular}

\section{Results and Discussion}

The successive linearization method (SLM) has been applied to solve the nonlinear coupled boundary value problem arising due to double-diffusive convection from a vertical cone immersed in a viscous liquid. Cross-diffusion effects are taken into consideration. The parameters controlling the flow dynamics are the Prandtl number Pr, Schmidt number Sc, buoyancy ratio $\lambda$, Dufour number $\mathrm{D}_{\mathrm{f}}$, and the Soret number $\mathrm{Sr}$. We, however, do not discuss the effects of parameters such as the Prandtl and Schmidt numbers whose significance has been widely studied in the literature on double-diffusive convection in viscous liquids. We have thus fixed $\operatorname{Pr}=\mathrm{Sc}=1$ and instead focus attention on results pertaining to the other three important parameters. In addition, we restrict ourselves to parameter values in the interval $0 \leq \mathrm{D}_{\mathrm{f}}$, Sr $\leq 1$. To highlight the effect of buoyancy, for aiding buoyancy condition, we take $\lambda>0$ while, for opposing buoyancy, $\lambda<0$.

We first establish the robustness and accuracy of the successive linearization method (SLM) by comparing the SLM results with those obtained numerically and previous related studies in the literature. The Matlab inbuilt bvp4c routine and the shooting technique with Runge-Kutta-Fehlberg (RKF45) and Newton-Raphson schemes are used to obtain the numerical solutions.

Tables 1 and 2 show the results of $f^{\prime \prime}(0),-\theta^{\prime}(0)$, and $-\phi^{\prime}(0)$ for different parameter values. Table 1 gives the comparison of the SLM results in the absence of cross-diffusion 


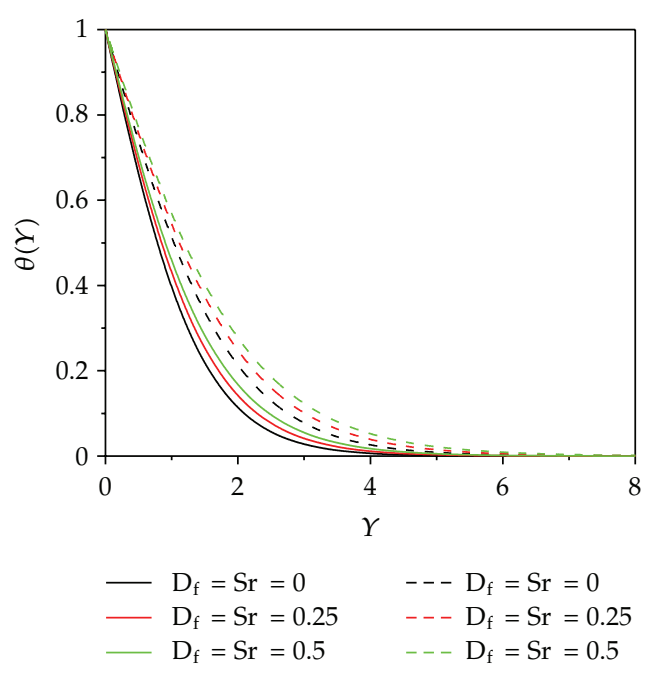

(a)

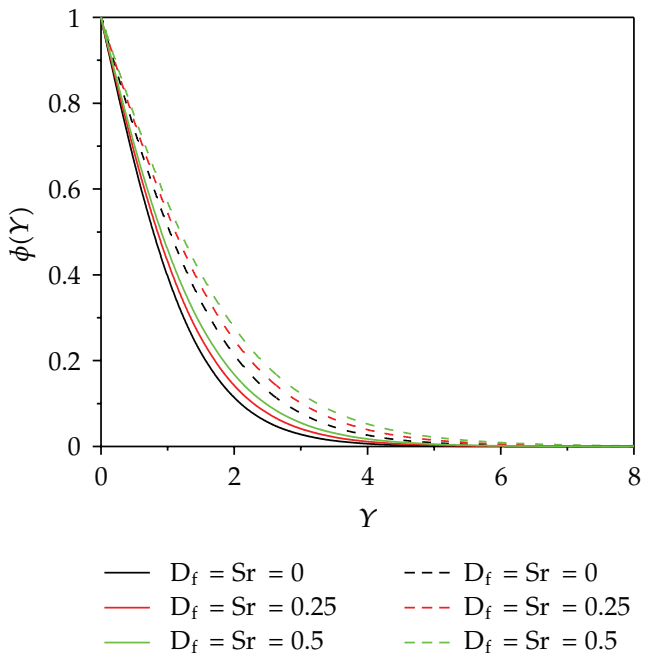

(b)

Figure 2: Cross-diffusion effect on (a) temperature and (b) concentration profiles with $\lambda=-0.5$ (dashed lines) and $\lambda=0.5$ (solid lines).

(i.e., $\mathrm{D}_{\mathrm{f}}=\mathrm{Sr}=\lambda=0$ ) with those presented by Ece [41]. The SLM solutions are found to be in excellent agreement with those of Ece [41] indicating the accuracy of the linearisation method.

Table 2 highlights both the accuracy and the accelerated convergence of the SLM for different values of $D_{\mathrm{f}}$ and Sr. The linearisation method converges to the numerical solutions at the fourth-order SLM for all values of $\mathrm{D}_{\mathrm{f}}$ and Sr. However, for larger values, convergence may require extra terms in the SLM solution series. It is evident that the SLM results are highly accurate as they match with those obtained by the bvp4c and the shooting technique up to the sixth significant digit.

It is to be noted from Table 2 that simultaneously increasing $D_{\mathrm{f}}$ and decreasing $\mathrm{Sr}$ lead to initial decreases in the skin-friction coefficient $f^{\prime \prime}(0)$ up to $\mathrm{D}_{\mathrm{f}}=\mathrm{Sr}=0.5$ and then start increasing. The heat transfer coefficient $-\theta^{\prime}(0)$ shows monotonic decrease, while the mass transfer coefficient exhibits the opposite change when subjected to simultaneous increase in $\mathrm{D}_{\mathrm{f}}$ and decrease in Sr.

To gain some insight into the dynamics of the problem, the temperature and concentration distributions are shown graphically in Figures 2-6. The Nusselt number $\mathrm{NuGr}^{-1 / 4}$ and Sherwood number ShGr ${ }^{-1 / 4}$ which highlight the heat and mass transfer are shown in Figures 7 and 8, as functions of $\mathrm{Sr}$ for different values of $\mathrm{D}_{\mathrm{f}}$ in the aiding and opposing buoyancy cases.

The variation of temperature and concentration profiles subject to a simultaneous increase in the cross-diffusion parameters $D_{f}$ and $\mathrm{Sr}$ is shown in Figure 2. We observe enhanced heat and mass transfer in the presence of the cross-diffusion effect as compared to the case $\mathrm{D}_{\mathrm{f}}=\mathrm{Sr}=0$ (no cross-diffusion). Increasing the cross-diffusion parameters increases both the thermal and species boundary layer thickness in both the aiding and opposing buoyancy situations. Hence, the cross-diffusion effect plays an important role in enhancing heat and mass transfer in double-diffusion convection processes. 


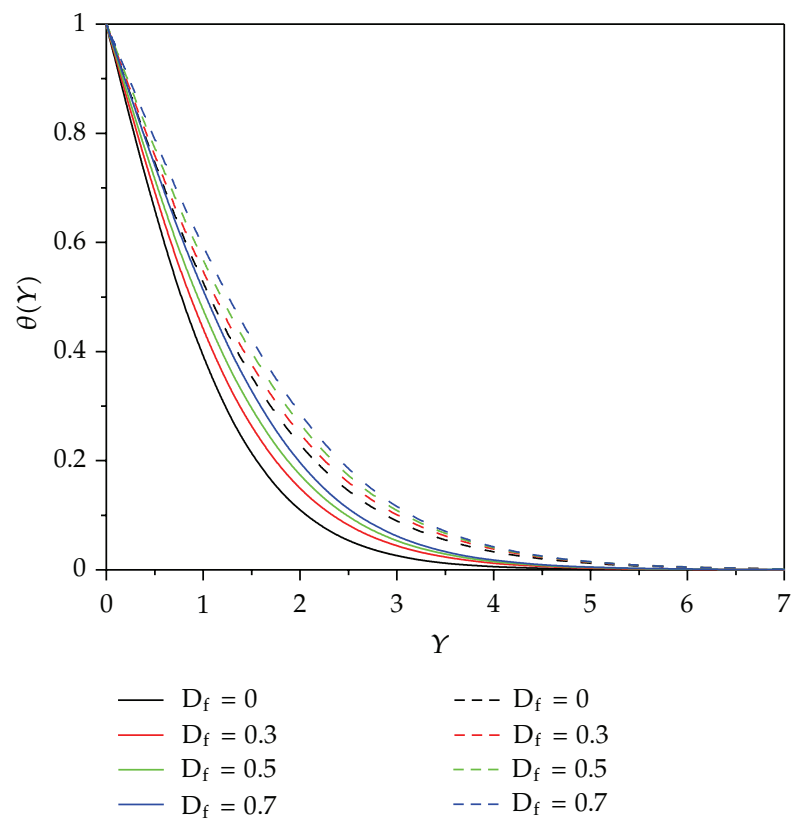

Figure 3: Effect of Dufour parameter $D_{\mathrm{f}}$ on $\theta(Y)$ with $\mathrm{Sr}=0.2, \lambda=-0.5$ (dashed lines), and $\lambda=0.5$ (solid lines).

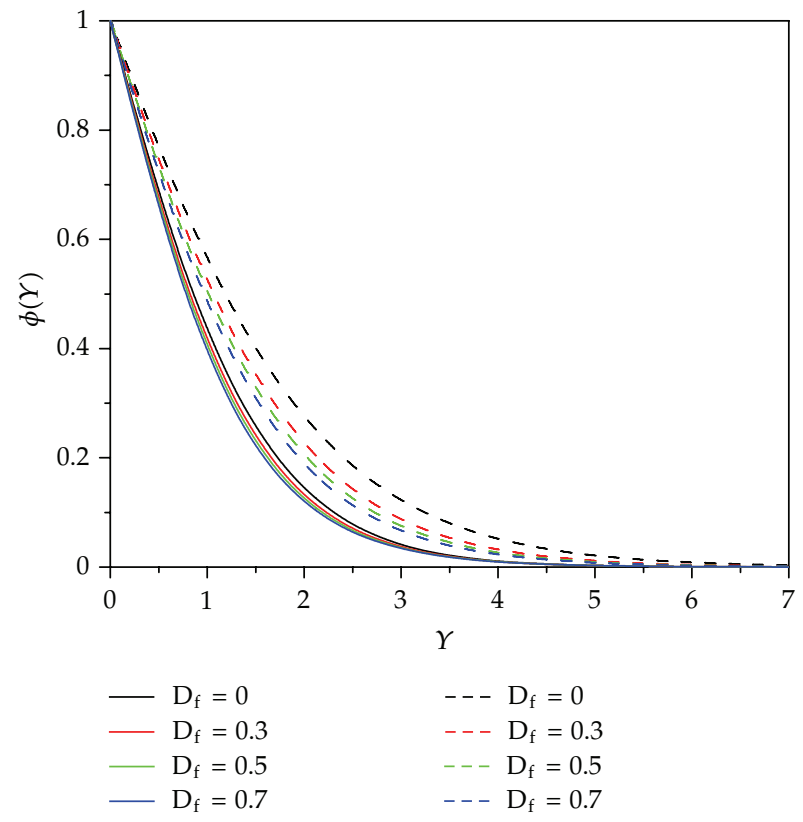

Figure 4: Effect of Dufour parameter $\mathrm{D}_{\mathrm{f}}$ on $\phi(Y)$ with $\mathrm{Sr}=0.2, \lambda=-0.5$ (dashed lines), and $\lambda=0.5$ (solid lines).

Figure 3 shows the effect of the Dufour number on the temperature distributions. The energy flux created by the concentration gradient gives rise to the Dufour effect or diffusionthermo effect and due to the increase in the energy flux created by concentration gradients, 


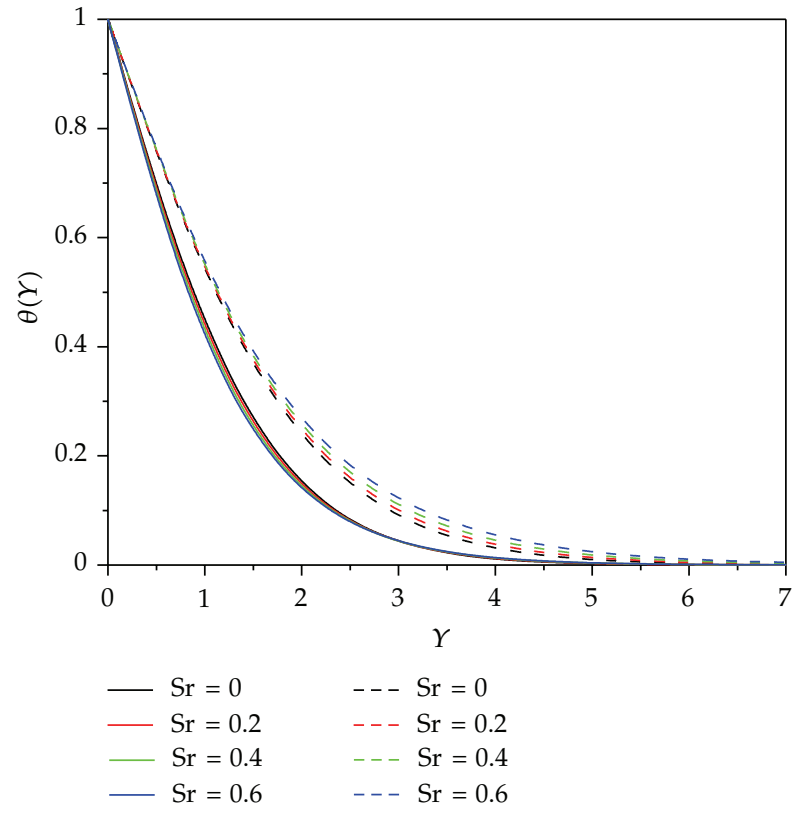

Figure 5: Effect of $\operatorname{Sr}$ on $\theta(Y)$ with $D_{\mathrm{f}}=0.3, \lambda=-0.5$ (dashed lines), and $\lambda=0.5$ (solid lines).

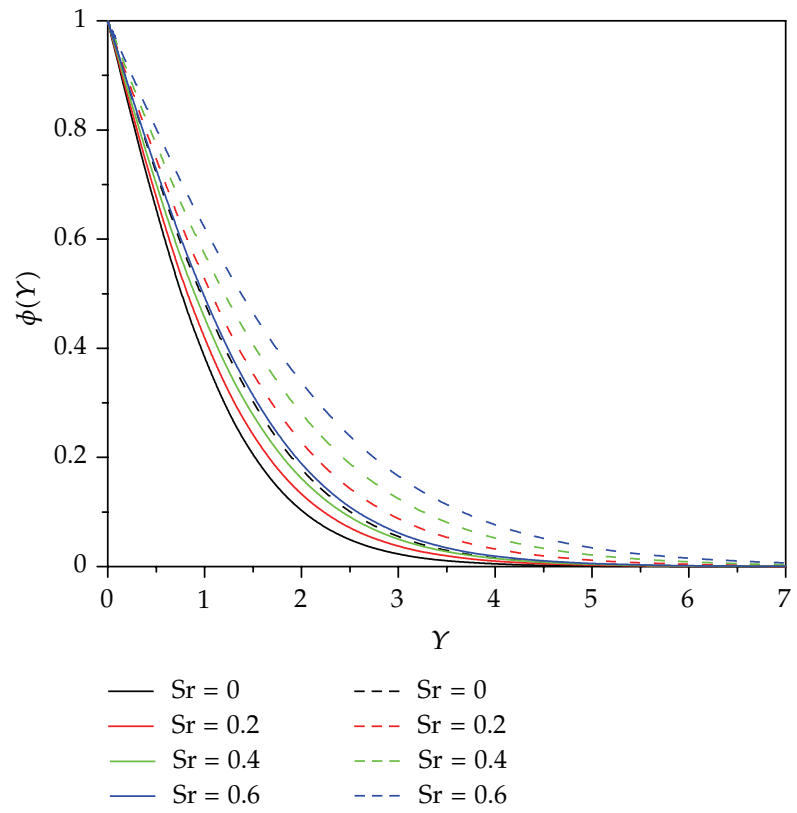

Figure 6: Effect of $\operatorname{Sr}$ on $\phi(Y)$ with $D_{\mathrm{f}}=0.3, \lambda=-0.5$ (dashed lines), and $\lambda=0.5$ (solid lines).

the temperature in the boundary layer increases significantly. The Dufour effect thus serves to thicken the thermal boundary layer. This trend is true for both aiding and opposing buoyancy scenarios.

Due to the coupling between the momentum, energy, and species balance equations, the Dufour parameter has an effect on the concentration boundary layer as well. This is 


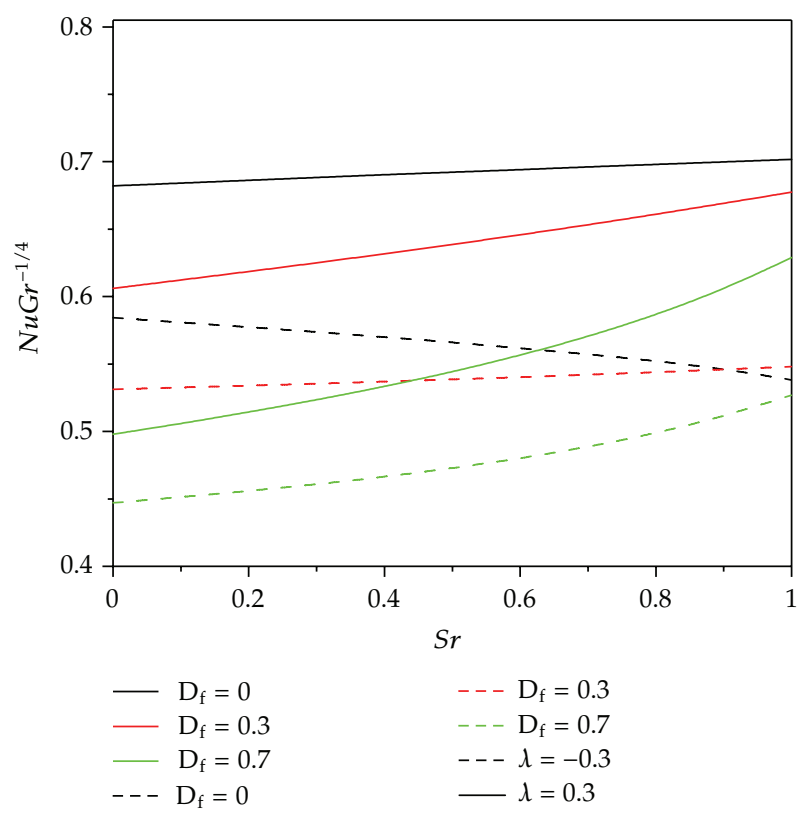

Figure 7: Variation of $\mathrm{NuGr}^{-1 / 4}$ with $\mathrm{Sr}$ for different values of $\mathrm{D}_{\mathrm{f}}$.

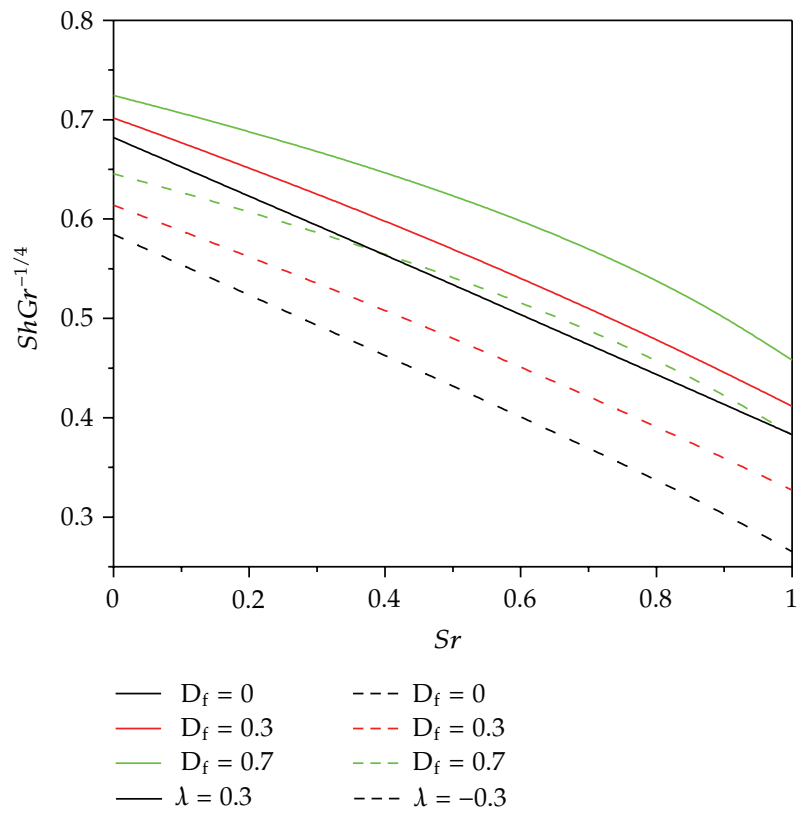

Figure 8: Variation of $\mathrm{ShGr}^{-1 / 4}$ with $\mathrm{Sr}$ for different values of $\mathrm{D}_{\mathrm{f}}$.

shown in Figure 4 where it is evident that $D_{\mathrm{f}}$ reduces the concentration in the boundary layer in both the cases of aiding and opposing buoyancy.

The effect of the Soret number on the temperature distribution is shown in Figure 5. The Soret parameter has a mixed effect on $\theta(Y)$ profiles. In the case of opposing buoyancy, 
increasing Soret parameter results in the thickening of the thermal boundary layer, while, in the aiding buoyancy case, the effect of Sr is exactly the opposite.

Figure 6 shows the effect of the Soret number on the species distribution in aiding and opposing buoyancy cases. The mass flux created by the temperature gradient gives rise to Soret or thermal-diffusion or thermophoresis effect. The thermophoretic force developed due to temperature gradients drives solute particles into the boundary layer region thereby increasing the concentration boundary layer as can be seen from Figure 6. The increase in concentration boundary with $\mathrm{Sr}$ is observed in both aiding and opposing buoyancy cases.

Figure 7 shows the Nusselt number $\mathrm{NuGr}^{-1 / 4}$ as a function of $\mathrm{Sr}$ for different values of $\mathrm{D}_{\mathrm{f}}$ in aiding and opposing buoyancy conditions. In the opposing buoyancy situation, $\mathrm{NuGr}^{-1 / 4}$ decreases with $\mathrm{Sr}$ for the case of pure thermophoresis $\left(\mathrm{D}_{\mathrm{f}}=0\right)$ and increases in the cross-diffusion case $\left(\mathrm{D}_{\mathrm{f}} \neq 0\right)$. In the aiding buoyancy situation, $\mathrm{NuGr}^{-1 / 4}$ increases monotonically with $\mathrm{Sr}$ for both $\mathrm{D}_{\mathrm{f}}=0$ and $\mathrm{D}_{\mathrm{f}} \neq 0$. The Dufour number reduces the heat transfer coefficient $\mathrm{NuGr}^{-1 / 4}$ in both aiding and opposing flow situations. Further, we observe enhanced heat transfer in the case of aiding buoyancy $(\lambda>0)$ as compared to the opposing buoyancy $(\lambda<0)$ case.

Figure 8 shows the mass transfer coefficient $\mathrm{ShGr}^{-1 / 4}$ as a function of $\mathrm{Sr}$ for different values of $\mathrm{D}_{\mathrm{f}}$ in aiding and opposing buoyancy conditions. In both aiding and opposing buoyancy situations, $\mathrm{ShGr}^{-1 / 4}$ is a decreasing function of $\mathrm{Sr}$ and an increasing function of $\mathrm{D}_{\mathrm{f}}$. There is also an increased mass transfer in the case of aiding buoyancy $(\lambda>0)$ as compared to the opposing buoyancy $(\lambda<0)$ case.

\title{
6. Conclusions
}

The problem of double-diffusive convection from a vertical cone was solved using a successive linearization algorithm in combination with a Chebyshev spectral collocation method. A comparison with results in the literature and numerical approximations showed that the SLM is highly accurate with assured and accelerated convergence rate thus confirming the SLM as an alternative semianalytic technique for solving nonlinear boundary value problems with a strong coupling. We found that the Dufour parameter reduces the heat transfer coefficient while increasing the mass transfer rate. In general, the effect of the Soret parameter is to increase the heat transfer coefficient and to reduce the mass transfer coefficient. Aiding buoyancy enhances heat and mass transfer compared to the opposing buoyancy condition.

\section{Nomenclature}

\author{
C: Concentration \\ $\bar{C}$ : Dimensionless concentration \\ $C_{f}$ : Local skin friction coefficient \\ $C_{r}$ : Concentration difference, $C_{w}-C_{\infty}$ \\ $f$ : Boundary layer stream function \\ $D$ : Solutal diffusivity \\ $\mathrm{D}_{\mathrm{f}}$ : Dufour number \\ g: Acceleration due to gravity \\ Gr: Grashof number \\ $J$ : Mass flux
}


$k$ : $\quad$ Thermal conductivity

$k_{1}, k_{2}$ : Cross-diffusion coefficients

$L: \quad$ Characteristic length

M: $\quad$ Order of successive linearization method

$N$ : Number of collocation points

$\mathrm{Nu}$ : Local Nusselt number

Pr: Prandtl number

q: $\quad$ Heat flux

$r: \quad$ Local radius of the cone, $x \sin \Omega$

$R: \quad$ Dimensionless local radius of the cone, $X \sin \Omega$

Sc: Schmidt number

Sh: Local Sherwood number

Sr: $\quad$ Soret number

T: $\quad$ Temperature

$\bar{T}: \quad$ Dimensionless temperature

$T_{r}: \quad$ Temperature difference, $T_{w}-T_{\infty}$

$U_{0}: \quad$ Reference velocity

$u, v$ : Velocity component in the $x, y$ directions

$U, V$ : Dimensionless velocity component in the $X, Y$ directions

$x, y$ : Coordinate measured along the surface and normal to it

$X, Y$ : Dimensionless coordinates.

\section{Greek Symbols}

$\alpha$ : Thermal diffusivity of the fluid

$\beta$ : Coefficient of thermal expansion of the fluid

$\beta^{*}$ : Coefficient of solutal expansion

$\Omega$ : Vertex half angle of the cone

$\lambda$ : Buoyancy ratio

$\mu$ : Coefficient of viscosity

$v$ : Coefficient of kinematic viscosity, $v=\mu / \rho$

$\theta$ : Boundary layer temperature

$\rho$ : Density of the fluid

$\psi$ : Dimensionless stream function

$\phi$ : Boundary layer concentration

$\xi$ : Collocation point

$\tau$ : Shearing stress.

Subscripts

$w$ : Quantities at the surface of the cone

$\infty$ : Quantities far away from the surface of the cone.

\section{Acknowledgments}

The authors wish to thank University of KwaZulu-Natal and the National Research Foundation (NRF) for financial support. 


\section{References}

[1] A. Mojtabi and M. C. Charrier-Mojtabi, "Double diffusive convection in porous media," in Handbook of Porous Media, pp. 269-320, 2nd edition, 2005.

[2] M. E. Stern, "The "salt fountain" and thermohaline convection," Tellus, vol. 12, pp. 172-175, 1960.

[3] M. E. Stern, "Collective instability of salt fingers," Journal of Fluid Mechanics, vol. 35, no. 2, pp. 209-218, 1969.

[4] D. A. Nield, "Onset of thermohaline convection in a porous medium," Water Resources Research, vol. 5, pp. 553-560, 1968.

[5] P. G. Baines and A. E. Gill, "On thermohaline convection with linear gradients," Journal of Fluid Mechanics, vol. 37, no. 2, pp. 289-306, 1969.

[6] J. Guo, Y. Qin, and P. N. Kaloni, "Non-linear stability problem of a rotating doubly diffusive fluid layer," International Journal of Engineering Science, vol. 32, no. 8, pp. 1207-1219, 1994.

[7] K. Khanafer and K. Vafai, "Double-diffusive mixed convection in a lid-driven enclosure filled with a fluid-saturated porous medium," Numerical Heat Transfer, Part A, vol. 42, no. 5, pp. 465-486, 2002.

[8] Sunil, A. Sharma, and R. C. Sharma, "Effect of dust particles on ferrofluid heated and soluted from below," International Journal of Thermal Sciences, vol. 45, no. 4, pp. 347-358, 2006.

[9] S. N. Gaikwad, M. S. Malashetty, and K. R. Prasad, "An analytical study of linear and nonlinear double diffusive convection in a fluid saturated anisotropic porous layer with Soret effect," Applied Mathematical Modelling, vol. 33, no. 9, pp. 3617-3635, 2009.

[10] C. Ping, "Similarity solutions for mixed convection from horizontal impermeable surfaces in saturated porous media," International Journal of Heat and Mass Transfer, vol. 20, no. 9, pp. 893-898, 1977.

[11] P. Cheng, "Natural convection in a porous medium: external flow," in Proceedings of the NATO Advanced Study in Natural Convection, Ezmir, Turkey, 1985.

[12] D. A. Nield and A. Bejan, Convection in Porous Media, Springer, Berlin, Germany, 3rd edition, 2010.

[13] D. B. Ingham and I. Pop, Transport Phenomenon in Porous Media, Elsevier, Oxford, UK, 2nd edition, 2002.

[14] A. J. Chamkha, "Coupled heat and mass transfer by natural convection about a truncated cone in the presence of magnetic field and radiation effects," Numerical Heat Transfer, Part A, vol. 39, no. 5, pp. 511-530, 2001.

[15] K. A. Yih, "Coupled heat and mass transfer by free convection over a truncated cone in porous media: VWT/VWC or VHF/VMF," Acta Mechanica, vol. 137, no. 1, pp. 83-97, 1999.

[16] R. G. Mortimer and H. Eyring, "Elementary transition state theory of the Soret and Dufour effects," Proceedings of the National Academy of Sciences of the United States of America, vol. 77, no. 4, pp. 17281731, 1980.

[17] L. Onsager, "Reciprocal relations in irreversible processes. I," Physical Review, vol. 37, no. 4, pp. 405426, 1931.

[18] N. G. Kafoussias and E. W. Williams, "Thermal-diffusion and diffusion-thermo effects on mixed freeforced convective and mass transfer boundary layer flow with temperature dependent viscosity," International Journal of Engineering Science, vol. 33, no. 9, pp. 1369-1384, 1995.

[19] F. G. Awad, P. Sibanda, and S. S. Motsa, "On the linear stability analysis of a Maxwell fluid with double-diffusive convection," Applied Mathematical Modelling, vol. 34, no. 11, pp. 3509-3517, 2010.

[20] M. S. Alam, M. M. Rahman, M. A. Maleque, and M. Ferdows, "Dufour and Soret effects on steady MHD combined free-forced convective and mass transfer flow past a semi-infinite vertical plate," Thammasat International Journal of Science and Technology, vol. 11, pp. 1-12, 2006.

[21] S. Shateyi, S. S. Motsa, and P. Sibanda, "The effects of thermal radiation, hall currents, soret, and dufour on MHD flow by mixed convection over a vertical surface in porous media," Mathematical Problems in Engineering, vol. 2010, Article ID 627475, 20 pages, 2010.

[22] F. G. Awad and P. Sibanda, "Dufour and Soret effects on heat and mass transfer in a micropolar fluid in a horizontal channel," WSEAS Transaction on Heat and Mass Trasfer, vol. 5, pp. 165-177, 2010.

[23] J. H. He and X. H. Wu, "Variational iteration method: new development and applications," Computers and Mathematics with Applications, vol. 54, pp. 115-123, 2007.

[24] J. H. He, "Coupling method of a homotopy technique and a perturbation technique for non-linear problems," International Journal of Non-Linear Mechanics, vol. 35, no. 1, pp. 37-43, 2000.

[25] J. H. He, "Homotopy perturbation method for solving boundary value problems," Physics Letters A, vol. 350, no. 1-2, pp. 87-88, 2006. 
[26] G. Adomian, "Nonlinear stochastic differential equations," Journal of Mathematical Analysis and Applications, vol. 55, no. 2, pp. 441-452, 1976.

[27] G. Adomian, "A review of the decomposition method and some recent results for nonlinear equations," Computers \& Mathematics with Applications, vol. 21, no. 5, pp. 101-127, 1991.

[28] S. Liao, Beyond Perturbation: Introduction to Homotopy Analysis Method, vol. 2 of CRC Series: Modern Mechanics and Mathematics, Chapman \& Hall/CRC, Boca Raton, Fla, USA, 2003.

[29] S. S. Motsa, P. Sibanda, and S. Shateyi, "A new spectral-homotopy analysis method for solving a nonlinear second order BVP," Communications in Nonlinear Science and Numerical Simulation, vol. 15, no. 9, pp. 2293-2302, 2010.

[30] S. S. Motsa, P. Sibanda, F. G. Awad, and S. Shateyi, "A new spectral-homotopy analysis method for the MHD Jeffery-Hamel problem," Computers and Fluids, vol. 39, no. 7, pp. 1219-1225, 2010.

[31] A. Yildirim, "Application of He's homotopy perturbation method for solving the Cauchy reactiondiffusion problem," Computers and Mathematics with Applications, vol. 57, no. 4, pp. 612-618, 2009.

[32] A. Yildırım and Z. Pınar, "Application of the exp-function method for solving nonlinear reactiondiffusion equations arising in mathematical biology," Computers \& Mathematics with Applications, vol. 60, no. 7, pp. 1873-1880, 2010.

[33] A. Yildirim and S. A. Sezer, "Analytical solution of linear and non-linear space-time fractional reaction-diffusion equations," International Journal of Chemical Reactor Engineering, vol. 8, article A110, 2010.

[34] A. Yildirim, A. Gökdogan, and M. Merdan, "Numerical approximations to solution of biochemical reaction model," International Journal of Chemical Reactor Engineering, vol. 9, article A92, 2011.

[35] Z. Z. Ganji, D. D. Ganji, and M. Esmaeilpour, "Study on nonlinear Jeffery-Hamel flow by He's semi-analytical methods and comparison with numerical results," Computers and Mathematics with Applications, vol. 58, no. 11-12, pp. 2107-2116, 2009.

[36] S. Ghafoori, M. Motevalli, M. G. Nejad, F. Shakeri, D. D. Ganji, and M. Jalaal, “Efficiency of differential transformation method for nonlinear oscillation: comparison with HPM and VIM," Current Applied Physics, vol. 11, no. 4, pp. 965-971, 2011.

[37] A. A. Joneidi, G. Domairry, and M. Babaelahi, "Three analytical methods applied to Jeffery-Hamel flow," Communications in Nonlinear Science and Numerical Simulation, vol. 15, no. 11, pp. 3423-3434, 2010.

[38] M. Babaelahi, G. Domairry, and A. A. Joneidi, "Viscoelastic MHD flow boundary layer over a stretching surface with viscous and ohmic dissipations," Meccanica, vol. 45, no. 6, pp. 817-827, 2010.

[39] Z. Makukula, S. Motsa, and P. Sibanda, "On a new solution for the viscoelastic squeezing flow between two parallel plates," Journal of Advanced Research in Applied Mathematics, vol. 2, no. 4, pp. 31-38, 2010.

[40] P. Sibanda, Z. G. Makukula, and S. S. Motsa, "A novel numerical technique for two-dimensional laminar flow between two moving porous walls," Mathematical Problems in Engineering, vol. 2010, Article ID 528956, 15 pages, 2010.

[41] M. C. Ece, "Free convection flow about a cone under mixed thermal boundary conditions and a magnetic field," Applied Mathematical Modelling, vol. 29, no. 11, pp. 1121-1134, 2005.

[42] C. Canuto, M. Y. Hussaini, A. Quarteroni, and T. A. Zang, Spectral Methods in Fluid Dynamics, Springer Series in Computational Physics, Springer, Berlin, Germany, 1988.

[43] W. S. Don and A. Solomonoff, "Accuracy and speed in computing the Chebyshev collocation derivative," SIAM Journal on Scientific Computing, vol. 16, no. 6, pp. 1253-1268, 1995.

[44] L. N. Trefethen, Spectral Methods in MATLAB, vol. 10 of Software, Environments, and Tools, SIAM, Philadelphia, Pa, USA, 2000. 


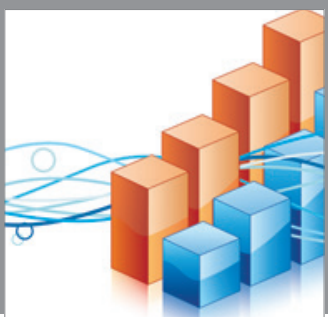

Advances in

Operations Research

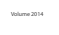

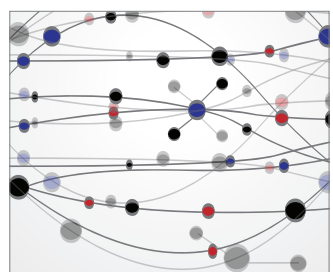

\section{The Scientific} World Journal
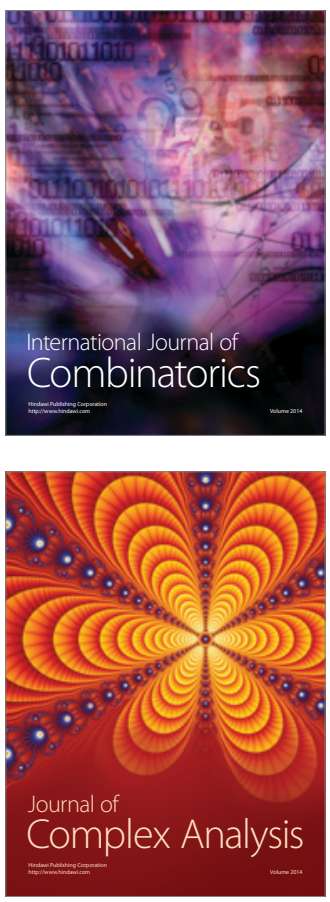

International Journal of

Mathematics and

Mathematical

Sciences
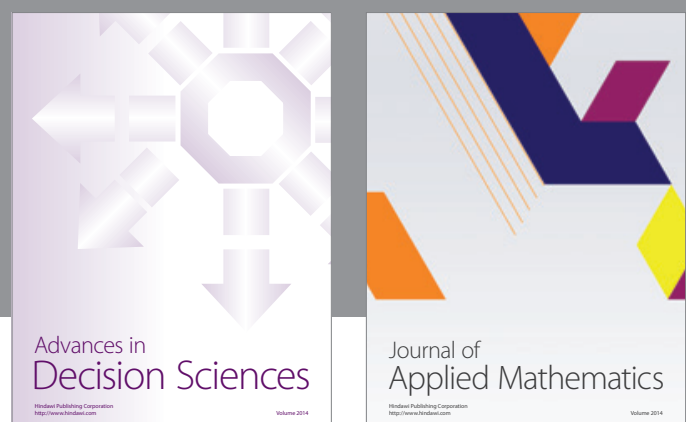

Journal of

Applied Mathematics
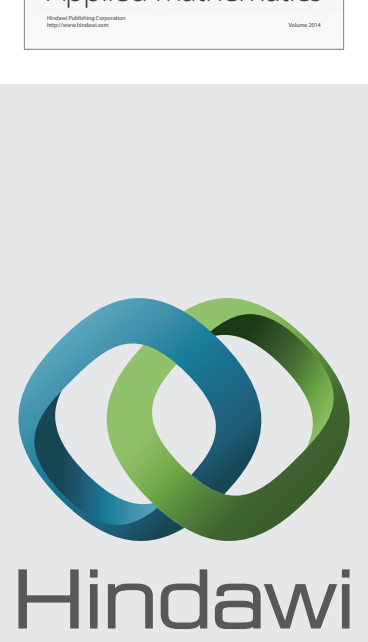

Submit your manuscripts at http://www.hindawi.com
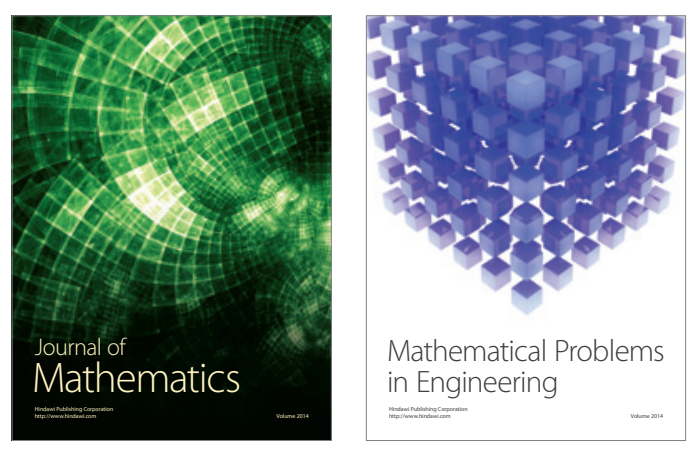

Mathematical Problems in Engineering
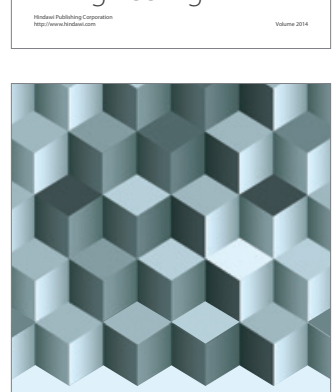

Journal of

Function Spaces
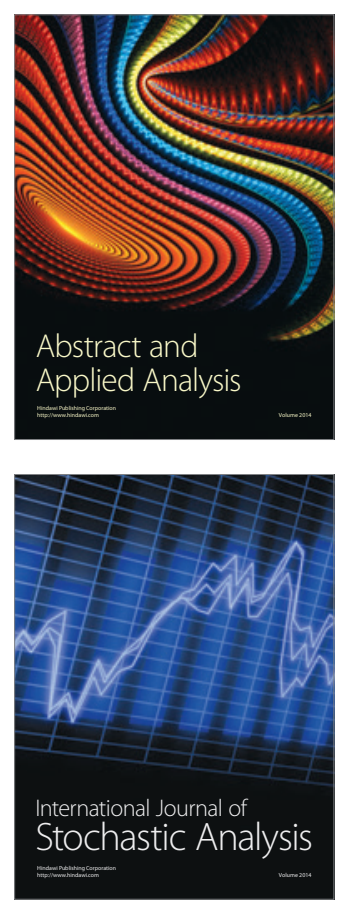

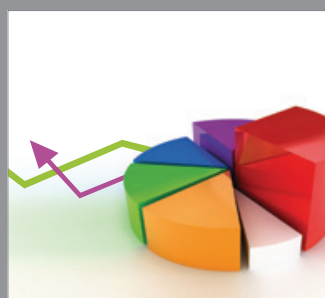

ournal of

Probability and Statistics

Promensencen
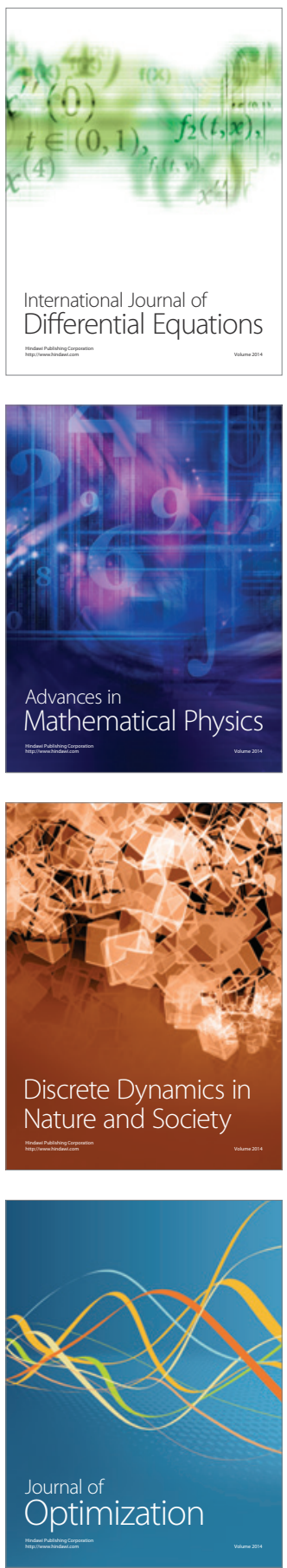